\title{
TASKS AND SUGGESTIONS FOR THE ADAPTATION TO THE CLIMATE CHANGE IN KECSKEMÉT
}

\author{
Edit Hoyk
}

\begin{abstract}
Department of Agroeconomy and Rural Development, Faculty of Horticulture and Rural Development, John von Neumann University, Hungary

Great Plain Research Department, Institute for Regional Studies, Centre for Economic and Regional Studies, Hungary

https://doi.org/10.47833/2020.2.AGR.024
\end{abstract}

\section{Keywords:}

climate change

adaptation

tasks

suggestions

Article history:

Received

Revised

Accepted

\begin{abstract}
Adapting to the expected negative impacts of climate change in our region is a strategic task in order to preserve the ecological conditions of the region and ensure the conditions for sustainable development. Responsible management of local water resources is essential (rainwater and purified sewage, saving water use) together with water supply, rational land-use change, deliberate management of green spaces, and eco-friendly urban planning/design. These serve both to preserve the natural features of the area, to ensure the sustainable use of landscape resources and to ensure the long-term viability and operability of the city.
\end{abstract}

\section{Introduction}

Climate change has already reached a level with irreversible consequences $[1 ; 2]$. These climatic and environmental impacts need to be adapted to prioritize the development and implementation of local adaptation options.

Adapting to the expected negative impacts of climate change in our region is a strategic task in order to preserve the ecological conditions of the region and ensure the conditions for sustainable development. Responsible management of local water resources is essential (rainwater and purified sewage, saving water use) together with water supply, rational land-use change, deliberate management of green spaces, and eco-friendly urban planning/design. These serve both to preserve the natural features of the area, to ensure the sustainable use of landscape resources and to ensure the long-term viability and operability of the city.

\section{Adaptation possibilities to the climate change in urban environment}

According to the findings of various international and domestic researches, Kecskemét and its wider region may be more and more threatened by the effects of climate change than before:

- heat waves

- stubble and forest fires

- extreme weather events (eg. wind storms, intense rainfalls, hails)

- drought, aridity

These events can have a profound effect not only on the fundamentals and opportunities of local farming and economic performance, and on the operability and quality of the built environment, but also on the health status of society. Therefore, local adaptation to climate change is a basic necessity and one of the greatest challenges of recent decades in today's society. The answers to the challenge will fundamentally determine Kecskemét's future development opportunities and longterm viability.

The following options for adaptation to the potential impacts of climate change are outlined: 


\section{Regard to heat waves:}

- It has a great importance that heat waves do not cause disruption to "critical infrastructures" (electricity, natural gas, fuel, district heating, drinking water and sewage; road and rail transport infrastructure; telecommunications and IT networks), and to minimize such disturbances.

- There is a need to develop and adopt a city heat-wave emergency plan. solutions.

- Urban ecological research should be launched to identify the potential impacts and possible

- Reflective coverings (eg. wall, roof, pavement, parking, road) should be encouraged to mitigate the urban heat island effect. Implementation of appropriate urban structure and urban design interventions (eg. open spaces, ventilated street structures, continuous large parks, building shielding technology).

- Planting plants and trees (because trees have a high degree of evaporation, reducing the maximum daytime temperatures and thus reducing the urban temperature).

- Promotion of alternative methods of building cooling.

- Establishment of institutional and contingency plans in the fields of health, social care and education.

- Establish a system of cooperation and continuous communication with emergency services, hospitals and other non-governmental organizations (eg. Hungarian Red Cross, Hungarian Maltese Charity Service) to reduce risks.

Regard to stubble and forest fires:

- Maintain, and, if necessary, improve the fire-fighting capacity of the fire brigade (provision of fire-fighting equipment and extinguishing agent, increased involvement of volunteer firefighters).

- Establish institutional and contingency plans to deal with emergencies.

- Fire detection sensors should be installed in the most vulnerable areas.

- Improving public information and awareness on nature protection and fire prevention.

Regard to extreme weather events:

- Effective use of ecosystem services and protection of biodiversity must be taken into account in land-use planning (the establishment of a system of ecological links and green belt networks will be a key issue).

- It has a great importance to ensure that extreme precipitation events do not cause disruption to „critical infrastructures”, but at least these disruptions are minimized.

- When planning water and waste management, the effects of extreme weather events must be taken into account, particularly when examining the adequacy of water management and sewerage systems. It is important to solve the problem of proper drainage of large amounts of rainwater and its storage and utilization on the spot (within the administrative boundaries of the city).

- Support the further development and improvement of the county's hail damage protection system (possibly using environmentally friendly compounds).

- Reduce surface parking rates in order to reduce car damage caused by hail.

- Strengthen urban forests, green infrastructures and contain urban and municipal sand soils to prevent dusting due to wind.

- Preparing the population for extreme weather events and the effects of climate change.

Regard to drought, aridity:

- Increasing water conservation is important for the quantitative protection of the settlement's water resources.

- Due to the sustainable use of the water base, it is a priority to reduce the use of water in the city and to use other sources (rainwater, purified sewage) to meet the water demand.

- There is a need to apply and promote gray water recovery methods.

- Establishment of a city-level rainwater management system (establishment of technical conditions for water management, establishment of surface drainage reservoirs and groundwater reservoirs) for water retention and water replenishment.

- Introduction of soil management practices that focus on moisture retention in agriculture.

- Increase the coverage of irrigated areas in both urban parks and agricultural areas. 
- Developing and applying efficient and water-saving irrigation techniques in urban areas.

- Provision of information to farmers: developing cooperation with agricultural research institutes, climate scientists, gathering international good examples to strengthen the climate adaptation of the agricultural sector.

The transport system and energy management play an important role in the effective implementation of adaptation. It is important for the city to make progress in the area of sustainable transport development. In this context, soft modes (eg. walking, cycling, electromobility) should be strengthened, needs to be expanded $P+R$ and $B+R$ network in the urban agglomeration and suburban areas, developing public transport, exploring different vehicle sharing options and developing the foundations for environmentally-based intelligent traffic management. Support should be given to making the city's fixed-track traffic, both in suburban transport - which is increasing (currently 20000 people per day) - and rail and road freight connect to industrial production.

Kecskemét is vulnerable to energy supply. Most of the energy consumed comes from outside the administrative boundaries, therefore during the operation of the city special attention should be paid to increasing energy security and energy saving (eg. continuation of panel modernization program, institutional heating and insulation, installation of solar panels, modernization of public lighting, energy efficiency (eg. complex development of district heating system, development of citylevel energy management system, professionalization of facility operation) and increased use of renewable energy sources (eg. construction of biomass heating plant, installation of solar plants [on underutilized areas], use of heat pumps and geothermal possibilities).

\section{Possibilities of $\mathrm{CO}_{2}$ absorption}

In order to develop an adequate urban microclimate and to absorb $\mathrm{CO}_{2}$, urban green areas need to be increased and their quality improved. This requires a greenfield infrastructure network development plan, as well as a complex municipal water management and rainwater recovery plan and its implementation.

Regarding to develop $\mathrm{CO}_{2}$ absorption capacity, the following provisions can be proposed:

- Improvement of green space of the city, increased protection of existing parks, forests and trees.

- Changing the outdated and incorrect soil management practices in agriculture, disseminating new methods (to increase crop yields and adapt to climate change more effectively).

- Protection of urban and peri-urban habitats, provision of ecological corridors and enhancement of inland green areas and outlying forests, consistent with ecological conditions (preferably with indigenous and non-allergenic species).

- Preservation of existing greened public spaces, public gardens and parks, improvement of their quality (planting of multi-level flora, improvement of conditions for irrigation with rainwater).

- Establishment of green roofs and green facades in as many buildings as possible in the city.

- Development of new community gardens, wooded areas and forests in underutilized areas.

- Reduce the number and size of surface car parks (establishment of underground car parks, park houses and automatic parking systems in designated areas), creation of parks and green public areas with multi-level flora instead of surface parking lots.

- Development of city-level rainwater management system and installation of automatic irrigation systems in public parks.

\section{Social challenges of the adaptation}

While the benefits of adaptation actions in Kecskemét are evident in Kecskemét, the benefits of local prevention actions are dispersed at regional and global level. However, beyond the purely ethical considerations (every member of society must do his or her best to mitigate climate change, regardless of the level of contribution), the city, through its size, financial, human and social capital, is responsible (eg. micro-regions, counties), preparing them for the effects of climate change, setting an example and disseminating good practices. Going beyond the administrative sphere, regional 
thinking and the implementation of local adaptation programs can have tangible results in the short term (eg. launching urban ecological research, expanding knowledge, strengthening the environmental industry and the emergence of new products and services, expanding cooperative relationships, increase in the number of good practices).

In the process of adapting to the negative effects of climate change, raising climate awareness is a shared responsibility of municipalities, involving urban decision-makers, professional organizations (research institutes, universities, civil society, interest protection organizations) and the general public.

In 2018, like the Bács-Kiskun County Municipality, the city joined the Covenant of Mayors, thereby committing itself to reducing its $\mathrm{CO}_{2}$ emissions $40 \%$ by 2030 compared to the base period of 2012 in key Covenant sectors (municipal buildings and facilities, service buildings and facilities, residential buildings, public lighting, municipal fleet, public transport, private commercial transport). In order to meet the obligations of accession, the recommendations and plans of the strategies, action plans and programs must be fully implemented, otherwise the ambitious target set for 2030 seems almost unattainable.

It is important for the city administration to be consistent with the principles, objectives and development directions set out in the various strategic documents (eg. Environmental Program, Climate Strategy, Sustainable Energy and Climate Action Plan, Urban Development Concept, Integrated Urban Development Strategy). The necessary interventions - after adequate public information and debate - should be carried out in a well-considered manner, with the responsibilities determined, in a scheduled manner, with the necessary resources. The preparation of strategic documents is not an end in itself, but a tool for the concrete and structured implementation of specific interventions.

All climate protection and adaptation initiatives that serve mitigation or adaptation should be supported. Some of them come from the bottom, such as the „10 Million Trees” movement, or the „Adopt a Park” program. The other part is a proposal from professional organizations (eg. water management and water retention, launching of urban ecological research, preparation of a green area network development plan), which may include basic and necessary professional interventions, but may also include policy requirements and interventions that can serve the city in the same way. All of these are worthy of constructive debate and social consensus.

Settlement-level climate protection and adaptation is inconceivable without a proper network of professional expertise and cooperating professional organizations. It has a great importance to launch local research and studies, develop appropriate programs and projects (exploring the real needs of the city), prepare tender documentation for generating resources, which cannot be imagined without the use of well-trained professionals and the cooperation and support of various professional organizations. Professionals should also play a key role in educating, informing, raising awareness, organizing and managing collaborative professional networks.

The success of climate protection and adaptation depends to a large extent on persuading the public and making them aware that climate change and its effects are not future events, but rather the present processes. Everyone can experience these processes themselves. The occurrence of certain events (such as urban floods, wind storms and hail damage, heat waves, overheated homes, or even flood-inland-water-drought damage to agriculture that can cause loss of income, lack of commodities and food prices, etc.) also the effects of climate change. These, in many cases, can only be moderately influenced by the individual (environmentally conscious thinking and behavior), while adapting to adverse effects is much more effective than at present, even at the individual level.

\section{Summary}

Summarizing the suggestions, it can be concluded that the state of the environmental elements of the city, the improvement of its climate exposure and the enforcement of local environmental and climate protection aspects can only be achieved through a broad social cooperation. Protecting our environment is a shared responsibility, Kecskemét must set a good example and commit itself to ensuring the quality of life of its smaller and wider area in the long term.

\section{Acknowledgment}


Thank you for the support of EFOP-3.6.1-16-2016-00006 „Developing and expanding research potential at John von Neumann University" project. This project is supported by the Hungarian State and the European Union, co-financed by the European Social Fund, under the Széchenyi 2020 program.

\section{References}

[1] IPCC (2014). Climate Change 2014 - Synthesis Report. Summary for Policymakers. https://www.ipcc.ch/site/assets/uploads/2018/02/AR5 SYR FINAL SPM.pdf

[2] Láng I. - Csete L. - Jolánkai M. (2007): A globális klímaváltozás: hazai hatások és válaszok - A VAHAVA jelentés. Szaktudás Kiadó Ház, Bp., p. 220. https://doi.org/10.1556/agrokem.56.2007.1.16 